\title{
Automating the mixing and spraying stage of the instant mashed potato process
}

\author{
Guillermo Morales-Romero ${ }^{1}$, Adrián Quispe-Andía ${ }^{2}$, Nicéforo Trinidad-Loli ${ }^{3}$, Beatriz Caycho-Salas ${ }^{4}$, \\ Teresa Guía-Altamirano ${ }^{5}$, Carlos Palacios-Huaraca ${ }^{6}$, Omar Chamorro-Atalaya $^{7}$ \\ 1,2,3,4,5 Universidad Nacional de Educación Enrique Guzmán y Valle, Lima, Perú \\ ${ }^{6}$ Universidad Tecnólogica del Perú, Lima, Perú \\ ${ }^{7}$ Faculty of Engineering and Management, National Technological University of Lima Sur, Lima, Perú
}

\section{Article Info}

Article history:

Received Apr 5, 2021

Revised Sep 17, 2021

Accepted Sep 20, 2021

\section{Keywords:}

Automation

Controller

Elaboration process

Mashed potatoes

Mixing stage

Spraying stage

\begin{abstract}
The article describes a control logic used to automate the mixing stage of the instant mashed potato process, in order to improve the quality of the final product. Thus, initially the characteristics of the automated process are detailed, specifying the programming logic on the programmable logic controller, to later demonstrate through a data collection process the percentage of improvement in the quality of the final product from the perspective of the users. Indicators: percentage of humidity in the mixing stage, water absorption index (IAA), water solubility index (ISA) and hydrogen potential $(\mathrm{pH})$. The development of the research concludes that the automation of the process, achieved that the IAA index and the ISA index, obtained in the spraying stage, improve by $8.13 \%$ and $23.05 \%$, respectively, finding analyzed values within the optimal ranges. This in turn reflected a $39.61 \%$ improvement with respect to the humidity percentage, measured in the mixing stage, thus improving the quality of the final product, which brings with it a significant increase of $84.44 \%$ in production levels.
\end{abstract}

This is an open access article under the CC BY-SA license.

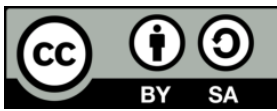

Corresponding Author:

Guillermo Morales-Romero

Universidad Nacional de Educación Enrique Guzmán y Valle

Av. Ciudad Sol de Collique, Calle 1, Comas, Lima, Peru

Email: gmorales@une.edu.pe

\section{INTRODUCTION}

The current problem for many companies that are part of the food industries is that many of these are not prepared to face the continuous innovation that global competitiveness requires [1]. The input transport process and its dosage in the food production process are often supervised by an operator [2]; this leads the operator to be more attentive to machine jams than to the quality of the final product [3]. Abbas et al. [4] pointed out that the decrease in productivity is also reflected by the dead times in which the machines are turned on but still, this due to jamming. Lopez [5], a case is described, with respect to a company dedicated to the food industry, in which the switching on and off of the production process is purely mechanical and manual, controlled by a staff who acted as operator, whose job was to flip a start and stop switch, this is the case [6] it is stated that in non-automatic processes, the function of the opposites is to interrupt the filling of inputs to obtain the product, said control strategy does not guarantee a balanced dosage of inputs.

Now in relation to the production process related to the production of instant yellow potato puree, in [7], it is pointed out that Peru has an enviable variety of potatoes, but its low industrialization generates limited development opportunities for its producers. In response to the problem mentioned in the previous paragraphs in [8]-[10] it is indicated that the manufacturing processes in the food industry are capable of 
being automated to improve efficiency with the use of low cost, low maintenance and high maintenance systems durability. In this regard, in [11]-[15], they state that automation is used in industry in order to achieve increased process efficiency and product quality and with this the competitiveness of companies.

Large-scale production involves repetitive tasks, where a set of magnitudes must also be maintained within established preset margins, so through industrial automation and process control it is possible to increase production levels [16]-[19]. Thus, industrial automation is defined as the transformation of processes carried out manually by processes that seek to self-regulate in order to improve the quality of the final product from the optimization of the resources of a production process [20]-[23]. Also, in [24], it is stated that the most important technologies for a company that contains different processes related to food production are those related to industrial automation, which will improve the efficiency of the equipment used in the production process.

In [25], the author states that automating the process related to the production of instant yellow potato puree guarantees an improvement in production time, as well as the quality of the final product. Also, in [26], what was said in the previous paragraph is reaffirmed, since it is specified that in the processing of potatoes to obtain mash, the automated systems guarantee to improve the quality, through the optimal dosage of the inputs used to obtain the product with the desired characteristics and quality. Along the same line of opinion in [27]-[29], they highlight that the greatest benefit of industrial automation is that it improves the quality of products because it inserts control strategies that, through sensors and final control elements, achieve selfregulate production indicators, very specifically in the imnense processes in dosing of substances and inputs in the food industry. In this sense, this article aims to describe the operation and functioning procedure of the automated process of making instant mashed potatoes, under the approach of programmed logic, that is, making use of a programmable logic controller, in order to achieve improve the quality of the final product.

\section{DATA COLLECTION}

\subsection{Data collection technique and instrument}

In the case of data collection, the technique of observation and documentary analysis was used, and the instrument used was a record sheet of the indicators under study. It should be noted that these indicators are the ones that are most closely related to the concentration in the production of instant potato puree, considering it as a quality factor of the production process. These indicators are the percentage of humidity in the mixing stage, the water absorption index (IAA), the water solubility index (ISA) and the hydrogen potential value $(\mathrm{pH})$. When these indicators are within the permissible range, it will be possible to visualize the improvement in the quality of the final product, thus increasing the quantity of production. For the analysis scenarios, that is, with the manual process and then with the automated process, measurement instruments were used such as the Fang Da $111 \mathrm{G}$ brand moisture meter, whose purpose was to capture the different values of the water absorption index (IAA) and the water solubility index (ISA) in the spraying stage, while, by means of a TEWS elektronik model MW 2300 meter, the percentage of humidity and pH was determined in the mixing stage. This collection was carried out for 30 days when the manual system was applied and then for 30 days once the automatic system was applied.

\section{PROCEDURE AND DEVELOPMENT OF THE AUTOMATION}

\subsection{Description of the automated process}

Next, Figure 1 outlines the operation and functioning procedure of the automated process for making instant mashed potatoes, under the focus of programmed logic. In Figure 1, the stages that are under the control of the programmable logic controller (PLC) siemens LOGO 230RC are highlighted, in which the process begins with the stage of transporting potato chips, whose operation will depend on the control established by the PLC. on the final elements (actuators). Once the above process is finished, the spraying process starts by driving a motor with a horizontal axis, in the low position a control strategy subjected to timed motor operation and relying on the mixing stage in which it is possible to dose adequately to through chemical inputs the concentration of mashed potatoes.

Next, the operation of each stage is described, referring to the elements considered in the general scheme of the production process of instant mashed potatoes, shown in Figure 2. From Figure 2 it can be pointed out that, in the transport stage, initially when the start button is pressed, the coil of the electric contactor that controls the ignition of the electric motor M1, of the vertical conveyor belt, will be actuated, which will carry the potatoes in flakes, to the spraying stage. The transport stage has a duration of 10 minutes, this time will be controlled by the TCRC1 timer, it should be noted that the potato chips are stored in a hopper, whose entry into the hopper will be carried out manually through an operator. After the 10 minutes of the transport stage have elapsed, in the spraying stage, the solenoid valve 1 (EV1) and the solenoid valve 2 (EV2) will open, which will give way to the powdered chemicals, whose opening of the 
valves will start to the dosing sub-stage, the duration of which will be 3 minutes, this time will be controlled by the TCRC2 timer. Once these inputs are entered, the electric motor M2 will be activated to start the spraying stage, for a time of 5 minutes, this time will be controlled by the TCRC 3 timer. It should be noted that all the timers are associated with the PLC connection delay timer function.

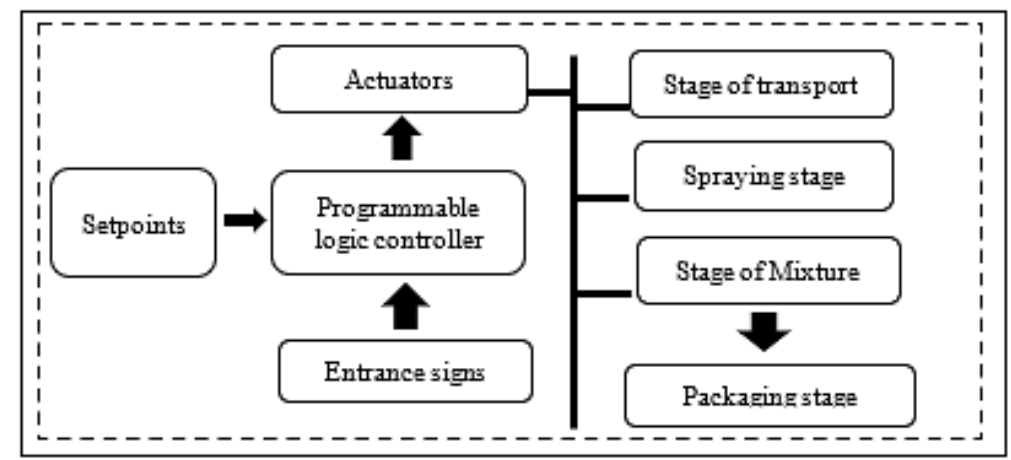

Figure 1. Scheme of the automated process for making instant mashed potatoes, under the approach of programmed logic

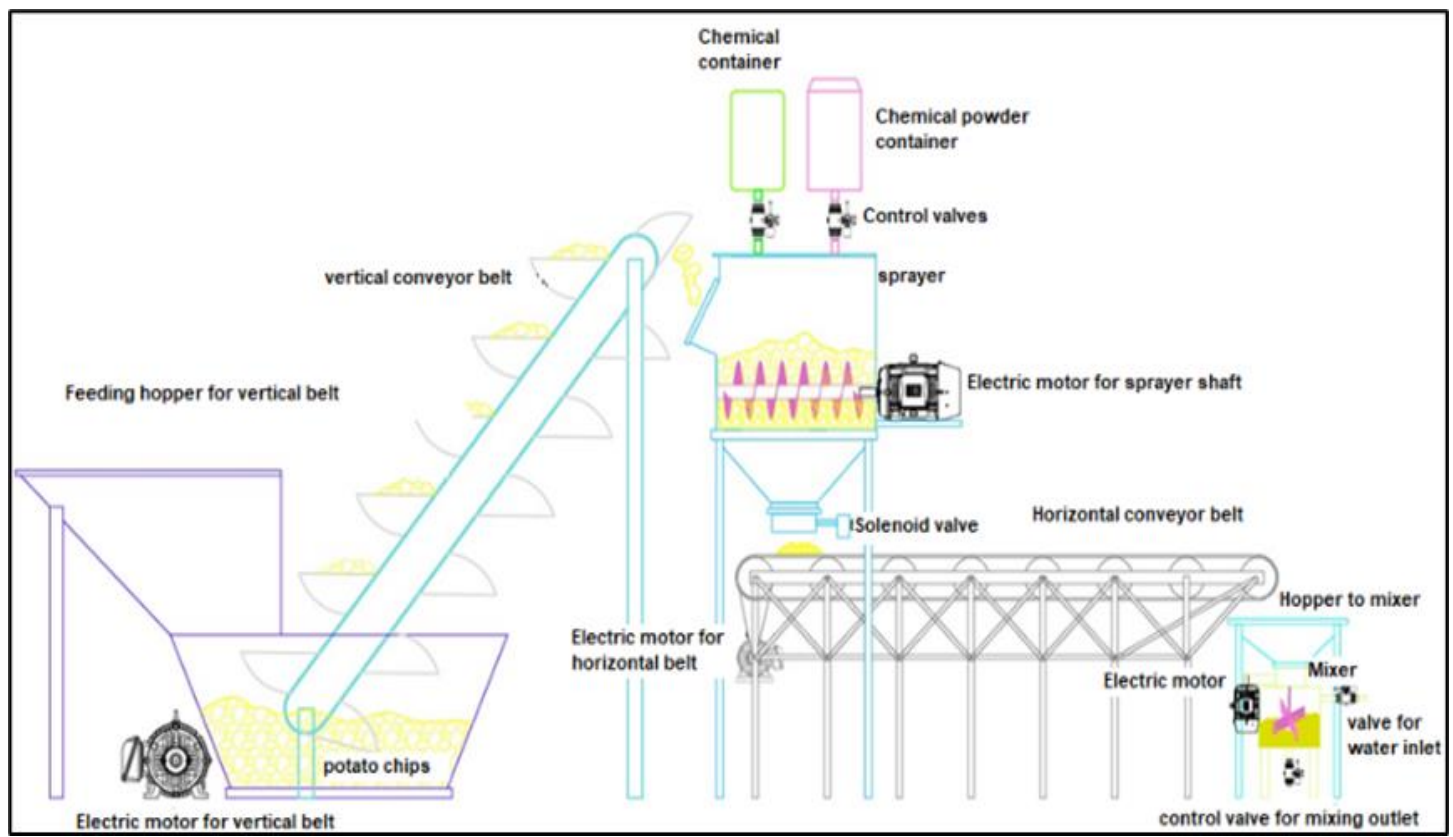

Figure 2. General diagram of the production process of instant mashed potatoes

After stopping the sprayer, the solenoid valve 3 (EV3) will open, which will output the mashed potato powder to the conveyor belt, this stage has a duration of 1 minute, this time will be controlled by the TCRC4 timer. It should be noted that once EV3 is open, the horizontal conveyor belt is automatically activated by turning on the M3 electric motor. The belt will transport the powdered potato puree to the hopper, which is connected to the mixer, this stage has a duration of 2 minutes, and this time will be controlled by the TCRC5 timer. Once all the supplies have been deposited in the mixer, the water delivery valve (EV4) will open, which will be activated for 2 minutes, this time will be controlled by the TCRC6 timer, once the water is drained, it will automatically be It will drive the electric motor of the M4 mixer, starting the mixing stage, this stage lasts 15 minutes, this time will be controlled by the TCRC7 timer. Once the mixing stage is finished, the control solenoid valve for the output of the mixture (EV5) will open, for a time of 5 minutes, controlled by the TCRC8 timer, this is where the product obtained is ready for the packaging stage in sacheteras machines. Based on what is described below, I proceed to show the programming of the programmable logic controller associating the programming with what is described in the previous paragraphs. 
In Figure 3, the start button (I1) is shown, which is responsible for actuating the coil of the electrical contactor (Q1) that will control the ignition of the electric motor M1, which operates the vertical conveyor belt. The operating time is determined by timer TCRC1 (B003). It is shown to the thermal relay I3 which will stop the process in case of overload. In addition, the mark M1 is observed, which is used to ensure that after 10 minutes the coil of the electric contactor that controls the electric motor M1 (Q1) is deactivated. The person responsible for stopping the entire automation is the stop button represented in the programming by input I2. In Figure 4, the programming of the spraying stage is shown, which refers to the EV1 solenoid valves (Q2) and the EV2 solenoid valve (Q3), the operating time is given by the timer TCRC2 (B004), in addition $\mathrm{I} 4$ represents the emergency stop switch of these elements, the person responsible for driving the sprayer is given by means of the coil of the contactor of the electric motor M2 (Q4), whose operating time will be determined by the timer TCR3 (B005), thus also I5 represents the emergency stop switch of this stage, as well as I6 represents in the programming the safety element of the electric motor M2. The actuation of the EV3 solenoid valve (Q5) will depend on the operating time set in the timer TCR4 (B008), furthermore I7 represents the emergency stop switch of this element, the person responsible for driving the horizontal conveyor belt is given by means of the coil of the contactor of the electric motor M3 (Q6), the operating time is given by the timer TCR5 (B009), finally in this programming segment I8 represents the emergency stop switch of this stage, as well as I9 represents the safety element of the electric motor M3.

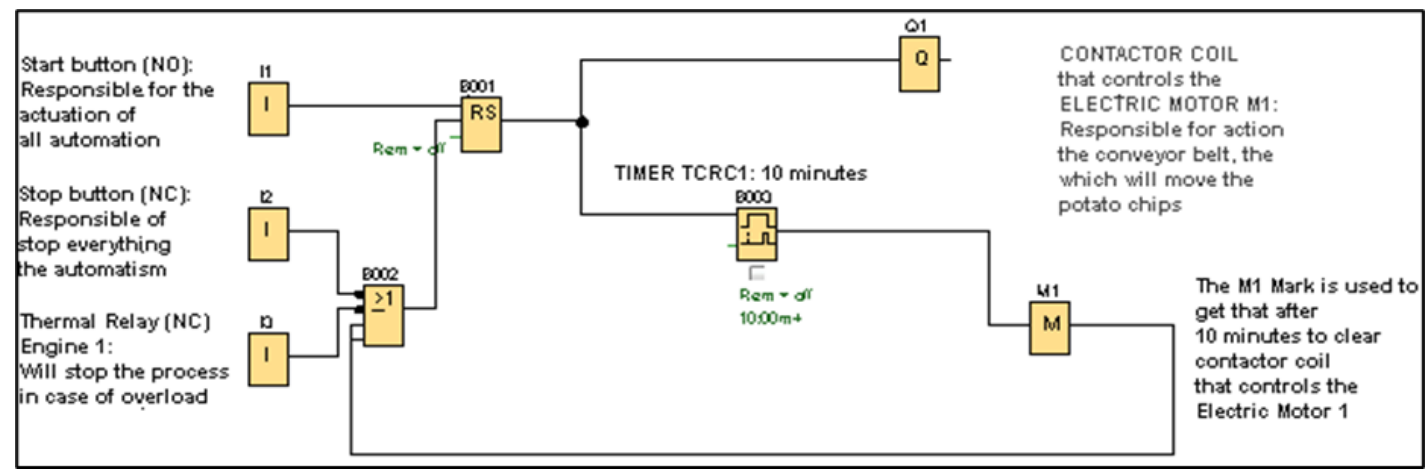

Figure 3. Programming segment in the PLC for the transport stage

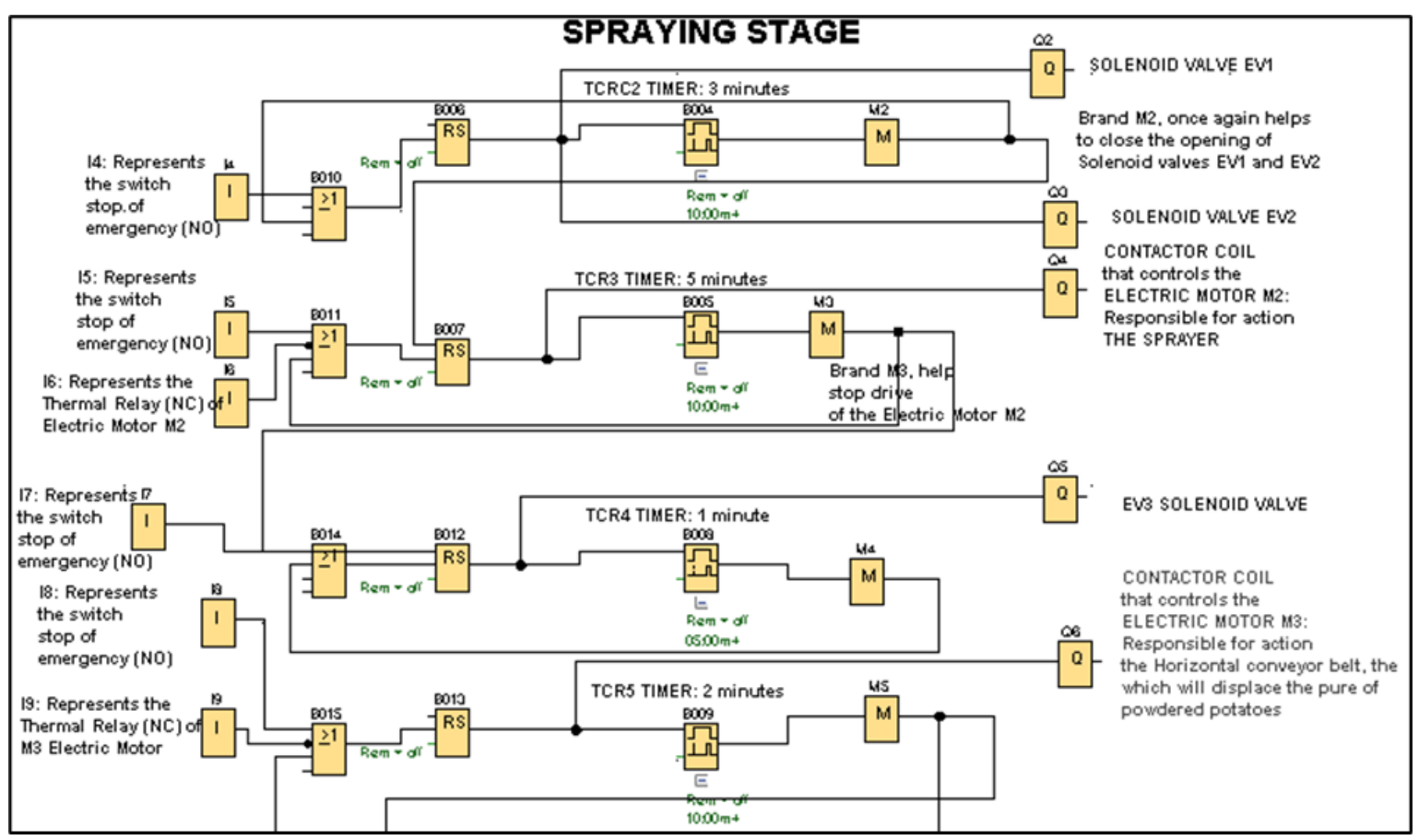

Figure 4. Programming segment in the PLC for the spraying stage 
In Figure 5, the programming segment of the mixing stage is shown, in which the solenoid valve EV4 (Q7), whose operating time is given by the timer TCR6 (B016), thus also I10 represents the emergency stop switch of this element, the person responsible for driving the mixer is given by means of the contactor coil of the electric motor M4 (Q8), the operating time of which is given by the timer TCR7 (B017), finally I11 represents the emergency stop switch of this stage, as well as I12 represents the safety element of the electric motor M4. It should be noted that in this programming segment the EV5 solenoid valve (Q9) is also shown, which will output the mashed potatoes to the sachette machine, the operating time is given by the timer TCR8 (B018) and I13 represents the emergency stop switch of this item. It should be noted that the term NO represents a normally open element, while the term $\mathrm{NC}$ represents a normally closed element.

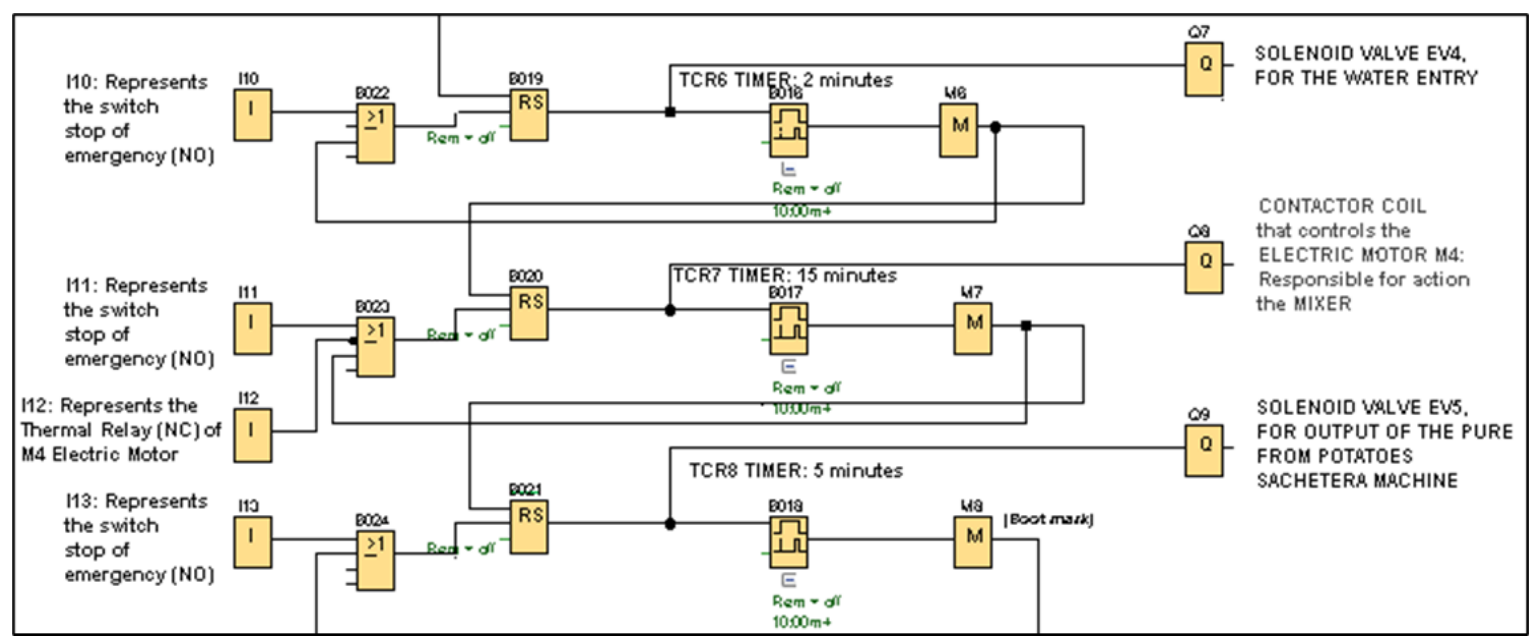

Figure 5. Programming segment in the PLC for the spraying stage

\section{RESULTS AND DISCUSSION}

\subsection{Results}

As indicated, at the point of data collection, the effect generated by the automation of the process on the quality of the final product is directly related to the desired value of the moisture percentage in the mixing stage, for this, the absorption index water (IAA) and the water solubility index (ISA), measured in the spraying stage, must be within the range allowed by the food and agriculture organization of the united nations (FAO). Figure 6 shows the results obtained with respect to the water absorption index (IAA).

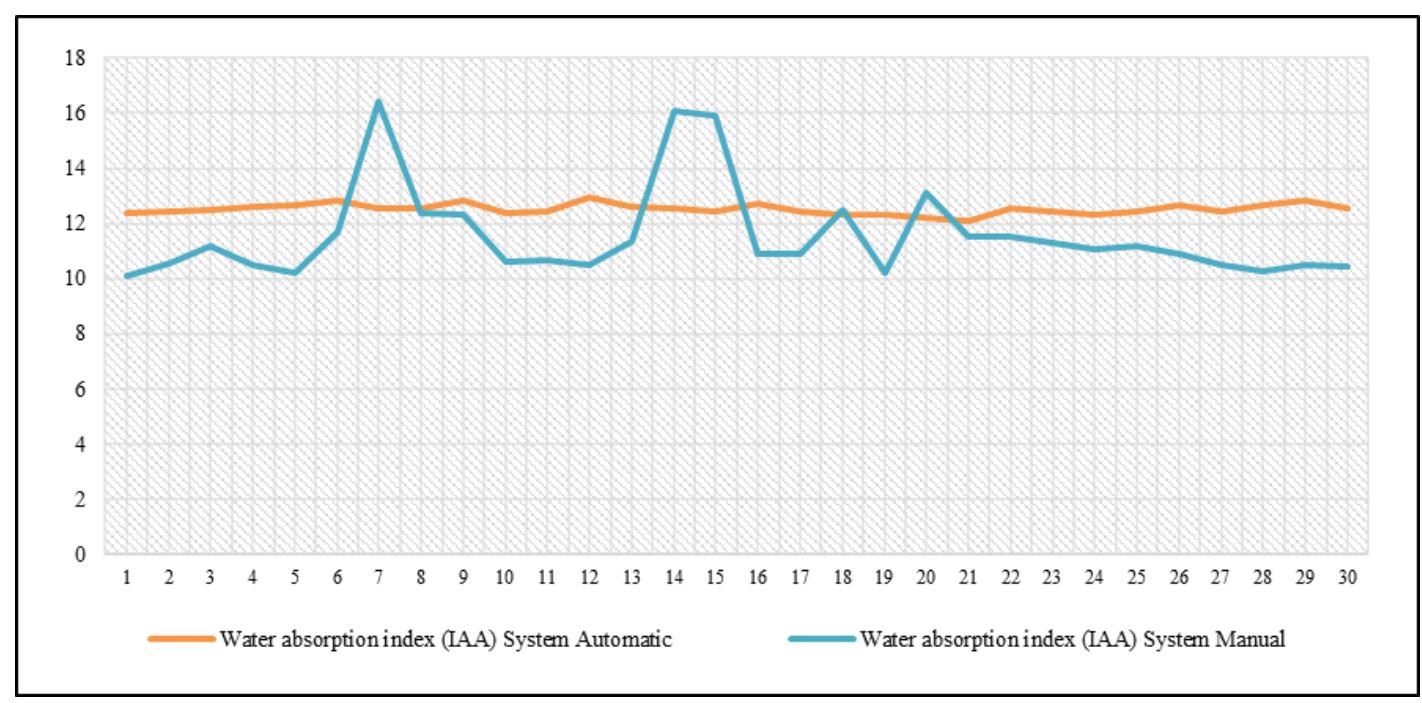

Figure 6. Variation of the water absorption index (IAA) 
Regarding the water absorption index (IAA), it can be observed in the previous figure that the automatic system does not present high variation peaks. Finding the values once the automation has been applied in a range of 12.11-12.97, which comply with what is established by the FAO, which indicates that the permissible values must be in the percentage range of 10,932-16,532. Likewise, in the manual system, since the IAA values are in a range of 10.1-16.45, it can be said that, when applying the automation, the water absorption index (IAA) has improved by $8.13 \%$. The results obtained regarding the water solubility index (ISA) are shown in Figure 7. In Figure 7, its evolution is graphically shown under the analysis of the two scenarios (before and after automation).

Regarding the water solubility index (ISA), it can be observed in the Figure 7, that once the automation has been applied, the ISA ranges are between 0.3-0.37; these values comply with what is established by FAO, which indicates that the values Allowable should be in the percentage range of 0.287-0.450. Likewise, in the manual system, since the ISA values are in a range of $0.18-0.57$, it can be said that, when applying the automation, the water solubility index (ISA) has improved by $23.05 \%$.

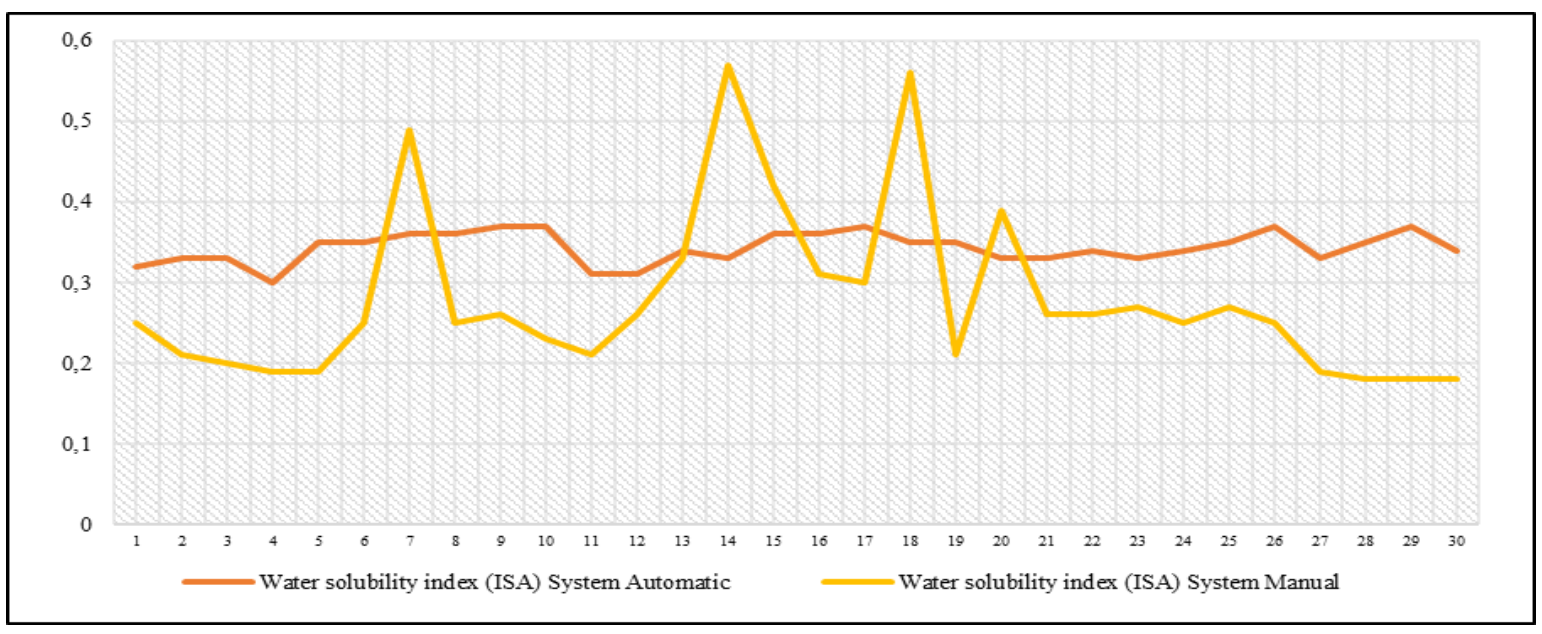

Figure 7. Variation of the solubility index in water (ISA)

Since these indicators are related to the percentage of moisture in the mixture, it is expected with this, to obtain improvement results in terms of the quality of the final product. The results obtained show that from the control of the moisture percentage of the product with the automated process, it is possible to comply with the minimum allowable standards for such indicator (percentage range of 5-8). On the other hand, in the manual system, the values of the humidity percentage were in a range of $4-8.1$, while with the automation the values are in the range of 6.9-7.5. For this reason, it can be said that, with the automated system, the humidity percentage was improved by $39.61 \%$.

The optimization of these indicators brings with it an improvement in the quality of the product that will be reflected in the increase in production. In other words, the production has experienced a significant increase of $84.44 \%$, this quantitatively translates to that $1268 \mathrm{~kg}$ are produced per month, compared to the manual process, where only $687.5 \mathrm{~kg}$ were produced, this is equivalent to $634 \mathrm{bags}$ of mashed potatoes being packaged per month, that is, 290 sachets of more than 2000 grams each, than was done before implementing automation.

\subsection{Discussion}

Through automation, it is possible to optimize the water absorption index (IAA) and the water solubility index (ISA), thus generating that the potato flour is within the sieving margin $(<0.22 \mathrm{~mm})$. When these optimal values are found, in the mixing stage the percentage of humidity (\%) improves by $39.61 \%$, compared to that obtained in the manual process, in this way the quality in the concentration of the final product will be improved. These results are similar to what is established in [30], where it is pointed out that automation improves the humidity percentage of the mashed potato mixture, by $26.7 \%$, since, in the 42 tests carried out, the humidity values were within of the established range. As indicated in the study of [31] the raw material in excess in the weighing stage went from 2 to $0.2 \mathrm{~kg}$ in five tests carried out after automation. The system, being more exact and precise in the composition of raw material, improves the quality of the final product. 
Regarding the results in the study of [32], it is pointed out that, since all the components of the system are with the correct design parameters, it is possible to improve the productivity of labor to $217.39 \mathrm{~kg}$ per man hour, the productivity of machine to $200 \mathrm{~kg}$ of Wantan pasta for each machine, the productivity of energy consumption in $17.15 \mathrm{~kg} / \mathrm{kWh}$ and the yield of the production volume in $100 \%$. With this improvement, the entire scheduled amount of production will be carried out with a $100 \%$ utilization of the machine. Consequently, automation manages to improve the indicators described and the hydrogen potential ( $\mathrm{pH}$ ) by $8.3 \%$.

As indicated in [33]-[37] with the implementation of the new automated system, it was possible to shorten the times in the task of filling the trucks, thus increasing the dispatch area to have a greater quantity of pelletized material for commercialization without requiring a decrease in the product demand. In addition, automation is taken as a security control measure for jobs that are considered high risk, thereby protecting the integrity of the working personnel, minimizing the danger and reducing the risk of an accident. Authors in [38]-[43] are indicating that automation processes in industry 4.0 provide greater speed and productivity in food processes. Using three PLCs that communicate via Profibus using the Master-Slave protocol, greater efficiency has been achieved in the filling, dosing, packaging and transport processes.

\section{CONCLUSION}

Food manufacturing and processing companies now use cost-effective automation solutions for higher production volumes compared to conventional processes, as automation has dramatically increased productivity compared to manual production systems, with the food industry standing out as the one with the greatest research and development potential. The opportunities are in the integration of sensors, human machine interaction (HMI), software control solutions. The use of technology allows companies to make competitive and innovative solutions.

The results of the present investigation indicate that automation, through the electronic instrumentation coupled to the controller, allows the precision in the dosage of inputs to be improved, which is reflected in the $39.61 \%$ improvement of the humidity percentage (\%), which is a vital factor in this production. However, this also led to the deduction that it is important to sustain this behavior from a calibration and adjustment plan for each measuring instrument used in the production process, in order to achieve continuous improvement. In general, automation brings with it a significant increase of $84.44 \%$ in production levels, in this way $580.5 \mathrm{~kg}$ is produced per month, more compared to the manual process. To further optimize productivity, it is recommended to carry out preventive and corrective maintenance, in order to avoid production stops that generate losses of raw material and other resources, due to the excessive amount of dust and material accumulated in the conveyor belts, which affects directly to the correct operation of the actuators.

\section{REFERENCES}

[1] F. Fareeza, C. Rambabu, S. Krishnaveni, and A. C. Kabiso, "Automation of DMPS manufacturing by Using LabView and PLC," International Journal of Electrical and Computer Engineering (IJECE), vol. 8, no. 6, pp. 5484-5494, 2018, doi: 10.11591/ijece.v8i6.pp5484-5494.

[2] V. Agravat, B. Khodifad, C. Matholiya, R. Swarnkar, and N. Kumar, "Food Process Industries: Island of Automation in Agriculture sector," Acta Scientific Agriculture, vol. 3, no. 12, pp. 85-86, 2019, doi: 10.31080/ASAG.2019.03.0729.

[3] Z. Aspar, N. Shaikh-Husin, and M. Khalil-Hani, "Algorithm to convert signal interpreted petri net models to programmable logic controller ladder logic diagram models," Indonesian Journal of Electrical Engineering and Computer Science (IJEECS), vol. 10, no. 2, pp. 905-916, 2018, doi: 10.11591/ijeecs.v10.i3.pp905-916.

[4] H. M. A. Abbas, R. F. Chisab, and M. J. Mnati, "Monitoring and controlling the speed and direction of a DC motor through FPGA and comparison of FPGA for speed and performance optimization," International Journal of Electrical and Computer Engineering (IJECE), vol. 11, no. 5, pp. 3903-3912, 2021, doi: 10.11591/ijece.v11i5.pp3903-3912.

[5] E. P. López, "Proposal for Automation in a finished product warehouse in a product manufacturing industry in Costa Rica," Journal InterSedes, vol. 16, no. 34, pp. 40-60, 2015.

[6] S. Narayan and C. Lakshminarayana, "Performance enhancement in active power filter (APF) by FPGA implementation," International Journal of Electrical and Computer Engineering (IJECE), vol. 8, no. 2, pp. 689-698, 2018, doi: 10.11591/ijece.v8i2.pp689-698.

[7] Q. Su, N. Kondo, D. Al Riza, and H. Habaragamuwa, "Potato Quality Grading Based on Depth Imaging and Convolutional Neural Network," Journal of Food Quality, vol. 2020, pp. 345-353, 2020, doi: 10.1155/2020/8815896.

[8] O. Chamorro-Atalaya et al., "Automatic control of motors through Simocode pro, and its effect on the performance of the process of filling and dispensing of chemical inputs," Indonesian Journal of Electrical Engineering and Computer Science (IJEECS), vol. 23, no. 1, pp. 179-187, 2021, doi: 10.11591/ijeecs.v23.i1.pp179-187. 
[9] M. Díaz-Choque et al., "Automated system for monitoring and control of the liquid wax production process," Indonesian Journal of Electrical Engineering and Computer Science (IJEECS), vol. 23, no. 2, pp. 782-790, 2021, doi: 10.11591/ijeecs.v23.i2.pp782-790.

[10] O. Chamorro-Atalaya, D. Goicochea-Vilela, D. A. Santillan, M. Diaz-Choque, and T. Diaz-Leyva, "Automation of the burner of a pirotubular boiler to improve the efficiency in the generation of steam," Indonesian Journal of Electrical Engineering and Computer Science (IJEECS), vol. 21, no. 1, pp. 101-109, 2021, doi: 10.11591/ijeecs.v21.11.pp101-109.

[11] C. Aguilar et al., "Emerging strategies for the development of food industries," Bioengineered Journal, vol. 10, no. 1, pp. 522-537, 2019, doi: 10.1080/21655979.2019.1682109.

[12] A. Abuelhaija, A. Jebrein, and T. Baldawi, "Swarm robotics: Design and implementation," International Journal of Electrical and Computer Engineering (IJECE), vol. 10, no. 2, pp. 2173-2181, 2020, doi: 10.11591/ijece.v10i2.pp2173-2181.

[13] R. Palanisamy, T. A. Singh, A. Ranjan, and J. Singh, "BLDC motor driven electric skateboard using SVPWM," International Journal of Electrical and Computer Engineering (IJECE), vol. 10, no. 1, pp. 711-718, 2020, doi: 10.11591/ijece.v10i1.pp711-718.

[14] M. Almaged, S. I. Khather, and A. I. Abdulla, "Design of a discrete PID controller based on identification data for a simscape buck boost converter model," International Journal of Power Electronics and Drive Systems (IJPEDS), vol. 10, no. 4, pp. 1797-1805, 2019, doi: 10.11591/ijpeds.v10.i4.1797-1805.

[15] G. Gonzalez-Filgueira and F. Rodriguez, "Automation of an industrial food plant through distributed control," RISTI (Revista Iberica de Sistemas e Tecnologias de Informacao), vol. 27, pp. 1-17, 2018.

[16] H. H. Aung and T. Z. Thein, "Simulation and Implementation of PLC Based for Detecting Burned Potato Chips and Remove using PLCSIM and HMI," International Journal of Trend in Scientific Research and Development, vol. 3, no. 5, pp. 1644-1649, 2019.

[17] K. Vengadakrishnan, N. Madhanakkumar, P. Pugazhendiran, C. Bharatiraja, and V. Sriramkumar, "Torque ripple minimization of PMBLDC motor using simple boost inverter," International Journal of Power Electronics and Drive Systems (IJPEDS), vol. 10, no. 4, pp. 1714-1723, 2019, doi: 10.11591/ijpeds.v10.i4.pp1714-1723.

[18] O. Chamorro-Atalaya, D. Arce-Santillan, T. Diaz-Leyva, and M. Diaz-Choque, "Supervision and control by SCADA of an automated fire system," Indonesian Journal of Electrical Engineering and Computer Science (IJEECS), vol. 21, no. 1, pp. 92-100, 2021, doi: 10.11591/ijeecs.v21.i1.pp92-100.

[19] J. J. Spies and B. Kotze, "Automated library booktruck for traditional libraries," Indonesian Journal of Electrical Engineering and Computer Science (IJEECS), vol. 15, no. 2, pp. 1095-1101, 2019, doi: 10.11591/ijeecs.v15.i2.pp1095-1101.

[20] L. B. Mite, C. A. A. Quiñonez, N. J. B. Chavarría, and K. N. B. Pacheco, "Automation and air conditioning levels in the corn sheller manufacturing process in Spanish Niveles de automatización y climatización en el proceso de fabricación de la desgranadora de maíz," Journal of Business and Entrepreneurial Studie, vol. 4, no.2, pp. 45-60, 2020, doi: 10.37956/jbes.v4i2.73.

[21] K. Kumar et al., "Soft computing and IoT based solar tracker," International Journal of Power Electronics and Drive Systems (IJPEDS), vol. 12, no. 3, pp. 1880-1889, 2021, doi: 10.11591/ijpeds.v12.i3.pp1880-1889.

[22] D. J. Almakhles, A. Swain, and H. Yuefeng, "Using sigma-delta quantizer based Pi for inductive power transfer systems," International Journal of Power Electronics and Drive Systems (IJPEDS), vol. 11, no. 3, pp. 1449-1458, 2020, doi: 10.11591/ijpeds.v11.i3.pp1449-1458.

[23] R. Ayop, S. M. Ayob, C. W. Tan, T. Sutikno, and M. J. A. Aziz, "Comparison of electronic load using linear regulator and boost converter," International Journal of Power Electronics and Drive Systems (IJPEDS), vol. 12, no. 3, pp. 1720-1728, 2021, doi: 10.11591/ijpeds.v12.i3.pp1720-1728.

[24] N. N. Tawfeeq, M. J. Marie, and K. S. Gaeid, "Computer control of teaching enhancement by communication networked," Indonesian Journal of Electrical Engineering and Computer Science (IJEECS), vol. 18, no. 2, pp. 736-744, 2020, doi: 10.11591/ijeecs.v18.i2.pp736-744.

[25] L. B. Mite, C. V. M. Mariela, D. M. Salvatierra, and K. A. Q. Ponce, "Analysis of the levels of automation of cocoa production processes in Spanish Análisis de los niveles de automatización de los procesos de producción de cacao," Journal of Business and Entrepreneurial Studies, vol. 4, no. 2, pp. 8-23, 2020, doi: 10.37956/jbes.v4i2.70.

[26] O. Martinez, C. Arguello, J. León, P. D. C. Carguacundo, and G. E. C. Daga "Prototype of automated irrigation system improves the yield of potatoes in Riobamba-Ecuador using wireless network sensors-WSN and 6LoWPAN," Makay Journal, vol. 9, no. 2, pp. 25-30, 2019, doi: 10.24133/maskay.v9i2.1058.

[27] O. K. Khutinaev, C. G. Dzhioeva, S. S. Basiev, D. P. Kozayeva, and I. G. Pliev, "Innovative technology for growing potato minitubers on aerohydroponic devices," IOP Conference Series: Earth and Environmental Science, vol. 624, 2021, pp. 1-70, doi: 10.1088/1755-1315/624/1/012054.

[28] E. C. A. Priya and G. T. S. Rajan, "An improved model of hybrid multi converter used for grid connected applications," International Journal of Power Electronics and Drive Systems (IJPEDS), vol. 10, no. 2, pp. 860-867, 2019, doi: 10.11591/ijpeds.v10.i2.pp860-867.

[29] M. I. A. Arafa and E. S. A. Said, "A different vision for uninterruptible load using hybrid solar-grid energy," International Journal of Power Electronics and Drive Systems (IJPEDS), vol. 10, no. 1, pp. 381-387, 2019, doi: 10.11591/ijpeds.v10n1.pp381-387.

[30] G. Michelson and S. Michelson, "Making production more efficient through modernisation and increased automatization. A case study at a potato production," Thesis, School of Industrial Engineering and Management, Norway, 2019. [Online] Available: http://www.diva-portal.org/smash/record.jsf?pid=diva2\%3A1374194\&dswid=-626 
[31] O. Cevallos, R. B. Acosta, K. B. Mora, and C. E. Muñoz, "Analysis of the levels of automation of industrial processes in a water bottling company in Spanish Análisis de los niveles de automatización de los procesos industriales en empresa envasadora de agua," Journal of Business and Entrepreneurial Studies, vol. 4, no. 2, pp. 24-31, 2020, doi: 10.37956/jbes.v4i2.71.

[32] L. E. Mera, M. Y. Ibarra, B. A. Menéndez, and B. J. Menéndez, "Analysis of the automation levels of the company produsiembal Cia. Ltda in Spanish Análisis de los niveles de automatización de la empresa produsiembal Cia. Ltda," Journal of Business and Entrepreneurial Studies, vol. 4, no. 2, pp. 107-113, 2020, doi: 10.37956/jbes.v4i2.80.

[33] M. P. Varghese, A. Manjunatha, and T. V. Snehaprabha, "The study on the effect of voltage ripple on multiphase buck converters with phase shedding control scheme for scada applications," Bulletin of Electrical Engineering and Informatics (BEEI), vol. 10, no. 4, pp. 1856-1863, 2021, doi: 10.11591/eei.v10i4.2798.

[34] I. H. Hamzah, M. S. Z. Suhaimi, A. A. Malik, and A. F. A. Rahim, "Design and implementation of HDL remote controller for smart home system," Indonesian Journal of Electrical Engineering and Computer Science (IJEECS), vol. 20, no. 1, pp. 117-124, 2020, doi: 10.11591/ijeecs.v20.i1.pp117-124.

[35] A. Saaed, "Elevator controller based on implementing a random access memory in FPGA," International Journal of Electrical and Computer Engineering (IJECE), vol. 11, no. 2, pp. 1053-1062, 2021, doi: 10.11591/ijece.v11i2.pp1053-1062.

[36] I. Shchur, V. Shchur, I. Bilyakovskyy, and M. Khai, "Hardware in the loop simulative setup for testing the combined heat power generating wind turbine," International Journal of Power Electronics and Drive Systems (IJPEDS), vol. 12, no. 1, pp. 499-510, 2021, doi: 10.11591/ijpeds.v12.i1.pp499-510.

[37] M. Alaoui, H. Maker, A. Mouhsen, and H. Hihi, "Photovoltaic emulator of different solar array configurations under partial shading conditions using damping injection controller," International Journal of Power Electronics and Drive Systems (IJPEDS), vol. 11, no. 2, pp. 1019-1030, 2020, doi: 10.11591/ijpeds.v11.i2.pp1019-1030.

[38] T. H. Tan, C. Y. Ooi, and M. N. Marsono, "An FPGA-based network system with service-uninterrupted remote functional update," International Journal of Electrical and Computer Engineering (IJECE), vol. 11, no. 4, pp. 3222-3228, 2021, doi: 10.11591/ijece.v11i4.pp3222-3228.

[39] P. Alconcer, M. Calero, and N. Cedeño, "Automation of industrial processes in Spanish Automatización de los procesos industriales," Journal of Business and Entrepreneurial Studies, vol. 4, no. 2, pp. 123-131, 2020, doi: 10.37956/jbes.v4i2.82.

[40] A. F. H. A. Gani, A. A. Bakar, A. Ponniran, M. Hussainar, and M. A. N. Amran, "Design and development of PWM switching for 5-level multiphase interleaved DC/DC boost converter," Indonesian Journal of Electrical Engineering and Computer Science (IJEECS), vol. 17, no. 1, pp. 131-140, 2019, doi: 10.11591/ijeecs.v17.i1.pp131-140.

[41] F. E. H. Velasco, C. I. H. Velasco, and J. E. Candelo-Becerra, "DC-AC power inverter controlled analogically with zero hysteresis," International Journal of Electrical and Computer Engineering (IJECE), vol. 9, no. 6, pp. 4767-4776, 2019, doi: 10.11591/ijece.v9i6.pp4767-4776.

[42] H. Attia, "Evaluation of selective harmonic elimination pulse width modulation technique for unipolar single-phase H-bridge inverter: Comparative study," International Journal of Power Electronics and Drive Systems (IJPEDS), vol. 9, no. 3, pp. 1157-1165, 2018, doi: 10.11591/ijpeds.v9n3.pp1157-1165.

[43] N. Mohammed, K. A. Danapalasingam, and A. Majed, "Design, control and monitoring of an offline mobile battery energy storage system for a typical malaysian household load using PLC," International Journal of Power Electronics and Drive Systems (IJPEDS), vol. 9, no. 1, pp. 180-188, 2018, doi: 10.11591/ijpeds.v9.11.pp180-188. 